\title{
PROTOTIPE MONITORING KETINGGIAN AIR BENDUNGAN MELALUI MEDIA SOSIAL TWITTER BERBASIS MIKROKONTROLER ATMEGA-328PU
}

\author{
I G.M. Sugiri Arnawa ${ }^{1)}$, I G.A. P. Raka Agung ${ }^{2)}$
}

\begin{abstract}
The prototype of this dam water level monitoring function to provide information about the dam water level through social media twitter and speakers. Information on twitter social media can be found by following the twitter account of this tool. The prototype consists of a microcontroller Arduino Uno , HC - SR04 sensor , LCD , WTV020SD and the Ethernet Shield. Sensor HC - SR04, read the value of the dam water level based on emission and reflection of ultrasonic waves . Arduino Uno microcontroller will process and display the sensor input from HC - SR04 form of dam water level on the LCD and sent via ethernet shield to social media twitter. WTV020SD serves to ring the speaker on the water level $10 \mathrm{~cm}, 20 \mathrm{~cm}, 30 \mathrm{~cm}$ and $40 \mathrm{~cm}$. The sound emitted is the normal condition of the dam, flood alert, flood alert and flood. Water level measurement results on LCD , manual measurement and display on twitter social media have gotten the same results .
\end{abstract}

Intisari - Prototipe monitoring ketinggian air bendungan ini berfungsi untuk memberikan informasi ketinggian air bendungan melalui media sosial twitter dan speaker. Informasi pada media sosial twitter dapat diketahui pengguna twitter dengan mengikuti akun alat ini. Prototipe terdiri dari mikrokontroler Arduino Uno, sensor HC-SR04, LCD, WTV020SD dan Ethernet Shield. Sensor HC-SR04, membaca nilai ketinggian air bendungan berdasarkan pancaran dan pantulan gelombang ultrasonik.

\footnotetext{
1 Mahasiswa, Teknik Elektro dan Komputer Universitas Udayana, Jl Gunung Agung RT Padang Udayana Gn 8 No. 8 Denpasar Indonesia. Telp: 085737455545, email: degiri_91@yahoo.com

${ }^{2}$ Dosen Teknik Elektro dan Komputer Universitas Udayana, , $\mathrm{Br}$ Anggarkasih Medahan Gianyar Bali Indonesia, Tel. 081999898301;e-mail: igapraka@yahoo.co.id
}

Mikrokontroler Arduino Uno akan mengolah dan menampilkan masukan dari sensor HC-SR04 berupa ketinggian air bendungan pada LCD dan dikirim melalui ethernet shield ke media sosial twitter. WTV020SD berfungsi untuk membunyikan speaker pada ketinggian air $10 \mathrm{~cm}, 20$ $\mathrm{cm}, 30 \mathrm{~cm}$ dan $40 \mathrm{~cm}$. Suara yang dikeluarkan adalah kondisi bendungan normal, waspada banjir, siaga banjir dan bahaya banjir. Hasil pengukuran ketinggian air pada LCD, pengukuran secara manual dan tampilan pada media sosial twitter sudah mendapatkan hasil yang sama.

Kata kunci- Arduino; Ethernet; HC-SR04; WTV020SD.

\section{PENDAHULUAN}

Bencana alam, seperti banjir sering terjadi secara tidak terduga. Bahkan saat cuaca cerah, banjir bisa terjadi di hilir sungai karena ada kiriman air dalam jumlah yang besar dari hulu sungai. Walaupun di hulu sudah terdapat bendungan tapi meluapnya air bendungan bisa terjadi secara tidak terdugaduga. Dengan perkembangan informasi dan teknologi ketinggian air yang menyebabkan bencana banjir ini, dapat disampaikan melalui media sosial twitter.

Pengguna media sosial yang sedang mengikuti akun twitter sistem ini akan mengetahui ketinggian air bendungan yang biasanya menyebabkan banjir. Pengguna twitter bisa menginformasikan ketinggian air kepada masyarakat sekitar bendungan dan aliran sungai. Masyarakat yang melewati bendungan juga bisa mendengarkan suara ketinggian air ini secara langsung. Penyebaran informasi ini akan membuat lebih banyak masyarakat yang mengetahui ketinggian air bendungan dalam waktu yang lebih singkat.

Pada prototype ini untuk memonitoring ketinggian air digunakan sensor ultrasonik HC-SR04 dan data ketinggian air dapat dilihat pada display LCD $8 \times 2$ yang terpasang pada alat. Informasi ketinggian air ini juga dapat diketahui para pengguna media sosial twitter khususnya yang sering melalui jalan sekitar bendungan tersebut atau masyarakat sekitar aliran sungai tersebut. Informasi ketinggian air pada media sosial ini di upload secara otomatis oleh Ethernet Shield berdasarkan data yang didapat mikrokontroler melalui sensor HC-SR04 secara periodis. Agar masyarakat sekitar bendungan mengetahui ketinggian air bendungan, peralatan ini dilengkapi dengan modul WTV020SD. Keluaran dari modul WTV020SD adalah suara yang menginformasikan ketinggian air 
bendungan pada nilai-nilai yang sudah ditentukan. Diharapkan dengan penyebaran informasi ini kerugian akibat meluapnya bendungan bisa diminimalkan.

\section{KAJIAN PUSTAKA}

\subsection{Sensor Ultrasonik}

Sensor ultrasonik HC-SR04 menggunakan sonar untuk menentukan jarak terhadap sebuah objek, seperti yang dilakukan kelelawar atau lumba-lumba. Sensor ini memiliki akurasi dan pembacaan yang cukup baik. Operasionalnya tidak dipengaruhi oleh cahaya matahari atau material berwarna gelap, namun dipengaruhi oleh material akustik. Sensor ini memiliki spesifikasi jangkauan $2 \mathrm{~cm}-500 \mathrm{~cm}$ dengan resolusi $0.3 \mathrm{~cm}$, serta jangkauan sudut kurang dari 15 derajat [1].

\subsection{LCD}

LCD (Liquid Cristal Display) adalah salah satu jenis display elektronik yang dibuat dengan teknologi CMOS logic yang bekerja dengan tidak menghasilkan cahaya tetapi memantulkan cahaya yang ada di sekelilingnya terhadap front-lit atau mentransmisikan cahaya dari back-lit. LCD (Liquid Cristal Display) berfungsi sebagai penampil data baik dalam bentuk karakter, huruf, angka ataupun grafik[2].

\subsection{Mikrokontroler}

Mikrokontroler sering digunakan pada sistem yang tidak terlalu kompleks. Sistem yang menggunakan mikrokontroler sering disebut sebagai embedded system atau dedicated system. Embeded system adalah sistem pengendali yang tertanam pada suatu produk, sedangkan dedicated system adalah sistem pengendali yang dimaksudkan hanya untuk suatu fungsi tertentu. Sebagai contoh printer adalah suatu embedded system karena di dalamnya terdapat mikrokontroler sebagai pengendali dan juga dedicated system karena fungsi pengendali tersebut berfungsi hanya untuk menerima data[3].

\subsection{Arduino UNO}

Arduino UNO adalah sebuah board mikrokontroler yang didasarkan pada mikrokontroler ATmega328. Arduino UNO mempunyai 14 pin digital input/output (6 di antaranya dapat digunakan sebagai output PWM), 6 input analog, sebuah osilator Kristal $16 \mathrm{MHz}$, sebuah koneksi USB, sebuah power jack, sebuah ICSP header, dan sebuat tombol reset. Arduino UNO memuat semua yang dibutuhkan untuk menunjang mikrokontroler, mudah menghubungkan ke sebuah komputer dengan sebuah kabel USB atau mensuplainya dengan sebuah adaptor AC ke DC atau menggunakan baterai untuk memulainya.

Arduino Uno berbeda dari semua board Arduino sebelumnya, Arduino UNO tidak menggunakan chip driver FTDI USB-to-serial. Sebaliknya, fitur-fitur Atmega16U2 (Atmega8U2 sampai ke versi R2) diprogram sebagai sebuah pengubah USB ke serial. Revisi 2 dari board Arduino Uno mempunyai sebuah resistor yang menarik garis 8U2 HWB ke ground, yang membuatnya lebih mudah untuk diletakkan ke dalam DFU mode[4]. Tampilan board Arduino UNO bisa dilihat pada gambar 1 .

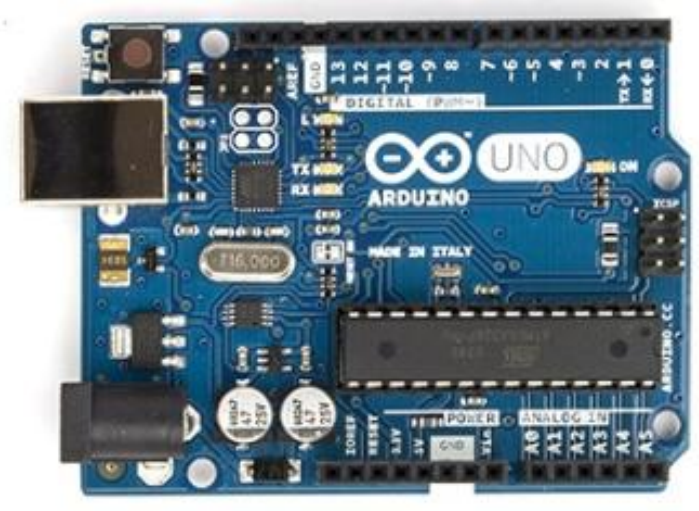

Gambar 1. Board arduino UNO [4]

\subsubsection{Bahasa Pemrograman Arduino}

ATmega328 pada Arduino Uno hadir dengan sebuah bootloader yang memungkinkan kita untuk mengupload kode baru ke ATmega328 tanpa menggunakan pemrogram hardware eksternal. ATmega328 berkomunikasi menggunakan protokol STK500 asli. Arduino UNO menggunakan bahasa $\mathrm{C}$ untuk pemrogramannya[4].

\subsection{WTV020SD}

Modul musik WTV020SD - 16P adalah alat elektronik yang dapat mengeluarkan suara sesuai dengan data pada kartu memory micro SD. Modul WTV020SD - 16P dapat mengeluarkan suara dalam format $\mathrm{aD} 4$ maka sebelum digunakan musik yang ingin didengarkan harus dikonversikan terlebih dahulu[5].

\subsection{Ethernet Shield}

Ethernet Shield adalah board untuk menghubungkan mikrokontroler dengan internet. menggunakan IC Wiznet W5100 chip Ethernet. IC wiznet W5100 menyediakan jaringan (IP) stack maupun TCP dan UDP. Untuk menghubungkan Ethernet Shield dengan komputer, hub, atau router digunakan 
kabel Ethernet standar (CAT5 atau CAT6 dengan konektor RJ45)[6].

\subsection{Twitter}

Twitter adalah layanan jejaring sosial yang memungkinkan penggunanya untuk mengirim dan membaca pesan berbasis teks hingga 140 karakter, yang dikenal dengan sebutan kicauan (tweet). Ada lima negara yang dianggap paling banyak menggunakan twitter. Negara terbanyak pertama adalah Amerika Serikat, kedua Jepang, ketiga Indonesia, keempat Inggris, dan kelima Brazil[7].

\section{METODE PERANCANGAN}

Metode perancangan prototipe monitoring ketinggian air bendungan melalui media sosial twitter berbasis mikrokontroler ATmega-328PU terdiri dari perancangan perangkat keras dan perancangan perangkat lunak. Perancangan perangkat keras terdiri dari bagian-bagian berikut yaitu :

1. Perancangan Rangkaian Mikrokontroler Arduino UNO.

2. Perancangan Rangkaian Sensor HC SR04.

3. Perancangan Rangkaian $L C D$.

4. Perancangan Rangkaian WTV020SD.

5. Perancangan Rangkaian Ethernet Shield.

Gambar 2 adalah diagram blok keseluruhan dari prototipe monitoring ketinggian air bendungan melalui media sosial twitter berbasis mikrokontroler ATmega-328PU.

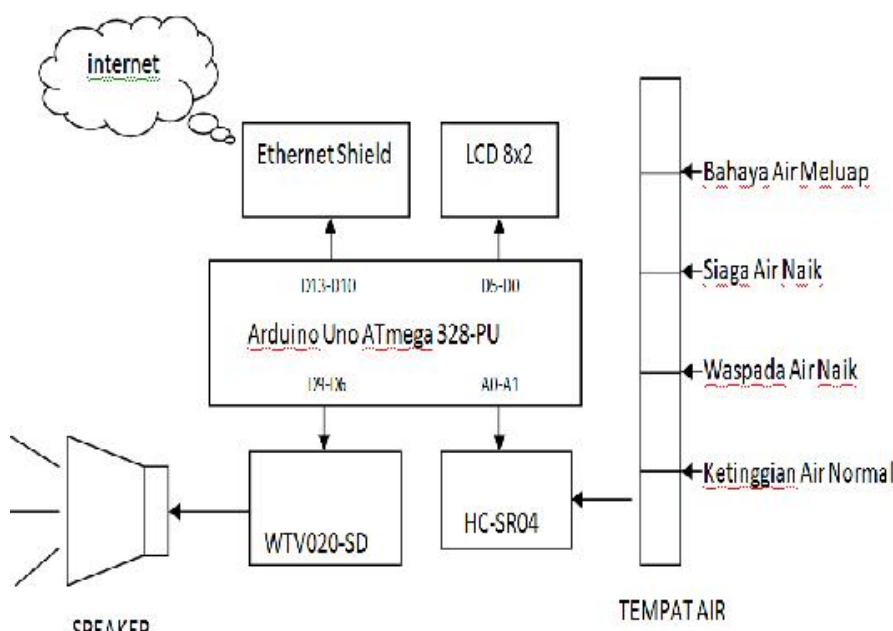

Gambar 2. Diagram blok keseluruhan perangkat keras .

Hasil perancangan perangkat keras secara keseluruhan bisa dilihat pada gambar 3 .

Gambar 4 memperlihatkan diagram alir perangkat lunak monitoring ketinggian air melalui media sosial twitter berbasis mikrokontroler ATmega-328pu.

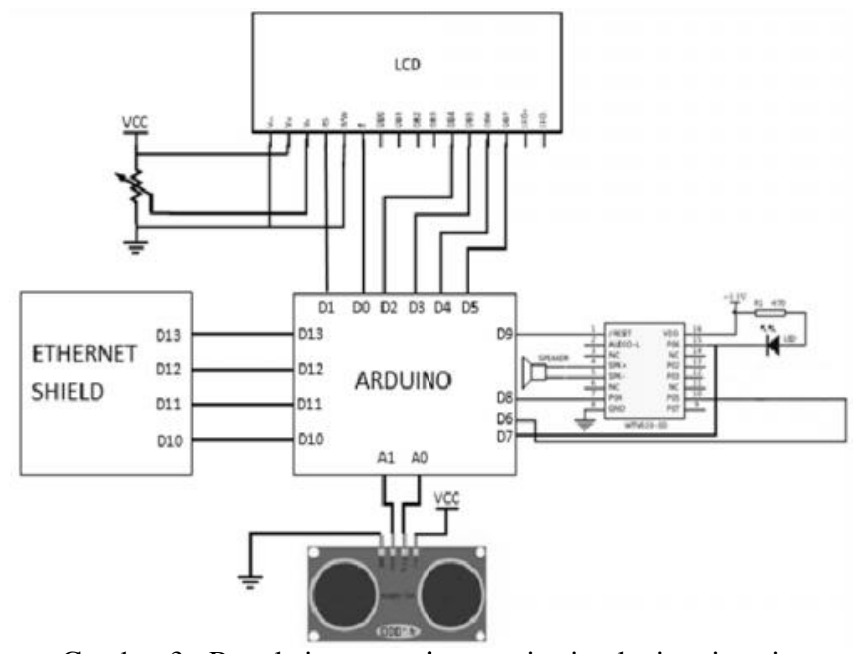

Gambar 3. Rangkaian prototipe monitoring ketinggian air bendungan berbasis mikrokontroler

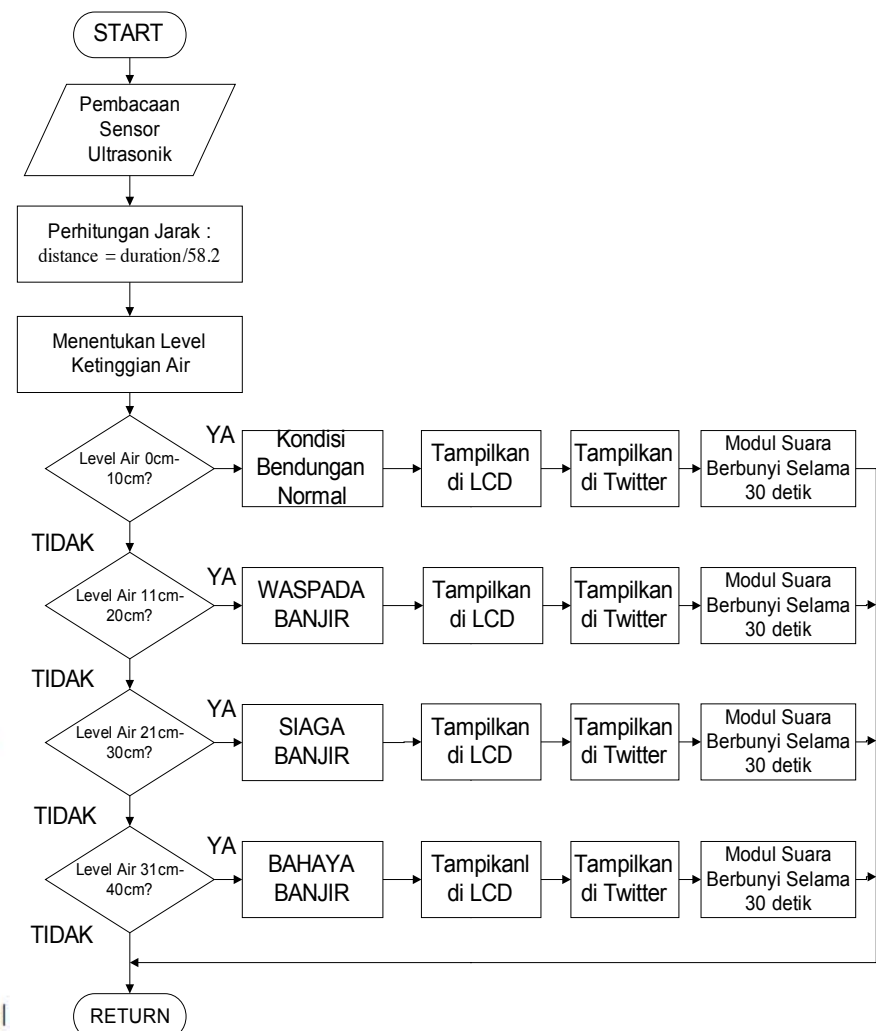

Gambar 4. Diagram alir perangkat lunak monitoring ketinggian air bendungan berbasis mikrokontroler

\section{HASIL DAN PEMBAHASAN}

\subsection{Realisasi Hasil Perancangan Prototype Monitoring Ketinggian Air Bendungan}

Realisasi prototipe perangkat monitoring ketinggian air bendungan melalui media sosial twitter berbasis mikrokontroler ATmega-328pu dapat dilihat pada gambar 5. 


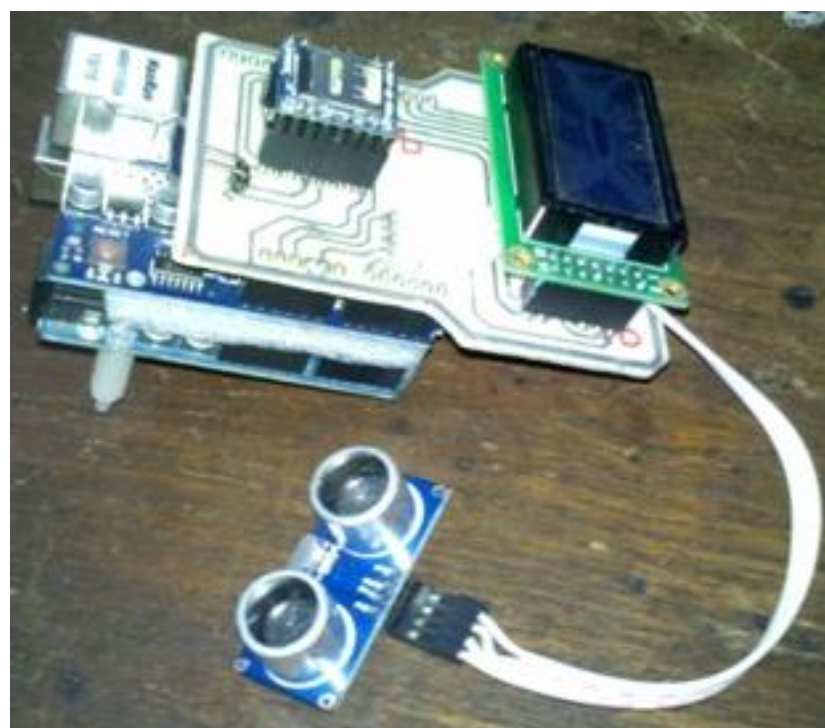

Gambar 5. Rangkaian keseluruhan prototype

\subsection{Pengujian Rangkaian $L C D$ dan Sensor HC SR04}

Diagram blok pengujian sensor HC-SR04 dan $L C D$ dengan Arduino Uno dapat dilihat pada gambar 6 .

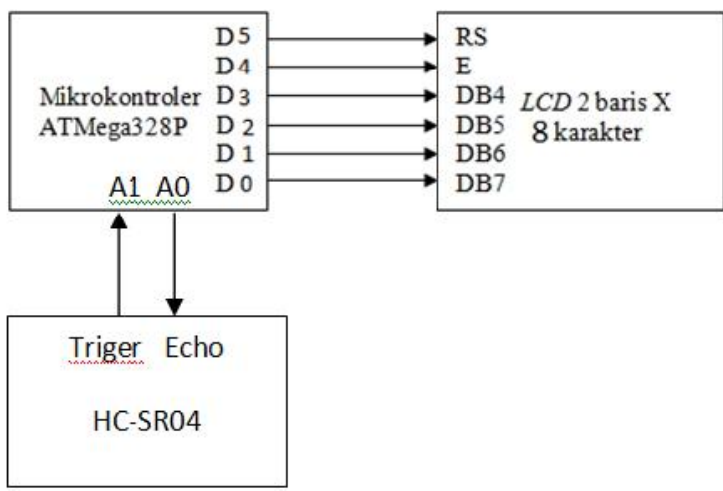

Gambar 6. Diagram blok pengujian $L C D$ dan sensor HC-Sr04

Tampilan dari salah satu hasil pengujian ketinggian air bendungan dengan sensor HC-SR04 bisa dilihat pada gambar 7. Hasil pengujian ketinggian air bendungan dengan sensor HC-SR04 yang ditampilkan pada $L C D$ dibandingkan hasil pengujian secara manual untuk beberapa ketinggian air bisa dilihat pada tabel 1 .

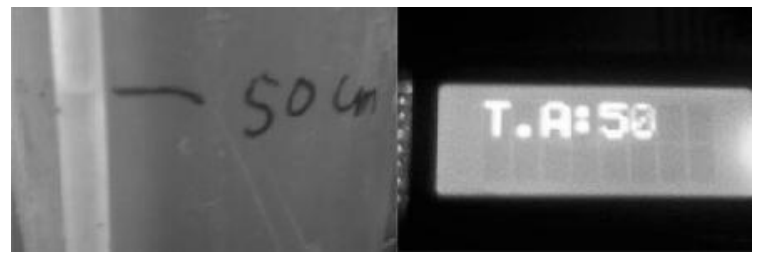

Gambar 7. Tampilan hasil pengukuran untuk ketinggian air $50 \mathrm{~cm}$
Tabel 1. Hasil pengujian sensor HC-SR04

\begin{tabular}{|l|l|}
\hline $\begin{array}{l}\text { Pengujian } \\
\text { Manual }\end{array}$ & $\begin{array}{l}\text { Hasil Pada } \\
\boldsymbol{C} \boldsymbol{D}\end{array}$ \\
\hline $5 \mathrm{~cm}$ & $5 \mathrm{~cm}$ \\
\hline $10 \mathrm{~cm}$ & $10 \mathrm{~cm}$ \\
\hline $15 \mathrm{~cm}$ & $15 \mathrm{~cm}$ \\
\hline $20 \mathrm{~cm}$ & $20 \mathrm{~cm}$ \\
\hline $25 \mathrm{~cm}$ & $25 \mathrm{~cm}$ \\
\hline $30 \mathrm{~cm}$ & $30 \mathrm{~cm}$ \\
\hline $35 \mathrm{~cm}$ & $35 \mathrm{~cm}$ \\
\hline $40 \mathrm{~cm}$ & $40 \mathrm{~cm}$ \\
\hline $45 \mathrm{~cm}$ & $45 \mathrm{~cm}$ \\
\hline $50 \mathrm{~cm}$ & $50 \mathrm{~cm}$ \\
\hline
\end{tabular}

\subsection{Pengujian Rangkaian WTV020SD}

Rangkaian WTV020SD berfungsi untuk membunyikan suara tahapan bahaya banjir. Diagram blok pengujian rangkaian WTV020SD dengan mikrokontroler Arduino UNO bisa dilihat pada gambar 8. Hasil pengujian secara keseluruhan dapat dilihat pada tabel 2.

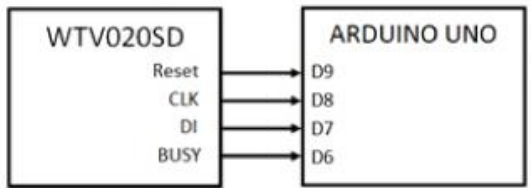

Gambar 8. Diagram blok pengujian rangkaian WTV020SD

Tabel 2. Hasil pengujian rangkaian WTV020SD.

\begin{tabular}{|l|l|}
\hline Ketinggian Air & Suara \\
\hline $10 \mathrm{~cm}$ & Bendungan Normal \\
\hline $20 \mathrm{~cm}$ & Waspada Banjir \\
\hline $30 \mathrm{~cm}$ & Siaga Banjir \\
\hline $40 \mathrm{~cm}$ & Bahaya Banjir \\
\hline
\end{tabular}

\subsection{Pengujian Ethernet Shield dengan Arduino}

Rangkaian Ethernet Shield berfungsi untuk mengirimkan informasi ketinggian air ke media sosial twitter. Pembaruan data ketinggian air dilakukan setiap 1 menit ke media sosial twitter melalui Ethernet Shield Gambar diagram blok pengujian mikrokontroler Arduino UNO dengan Ethernet Shield dapat dilihat pada gambar 8. Hasil pengujian Ethernet Shield pada tampilan twitter dapat dilihat pada gambar 9. Perangkat keras Ethernet Shield dengan Arduino UNO dapat dilihat pada gambar 10 .

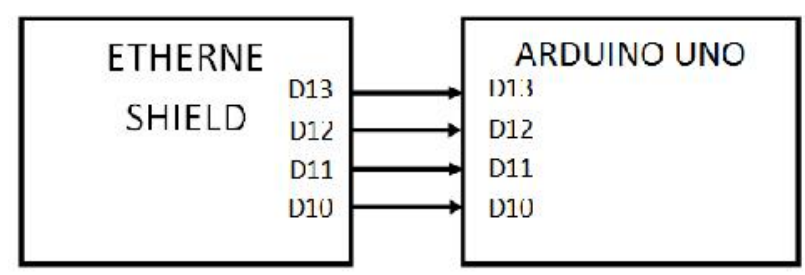

Gambar 8. Diagram blok pengujian Ethernet Shield 


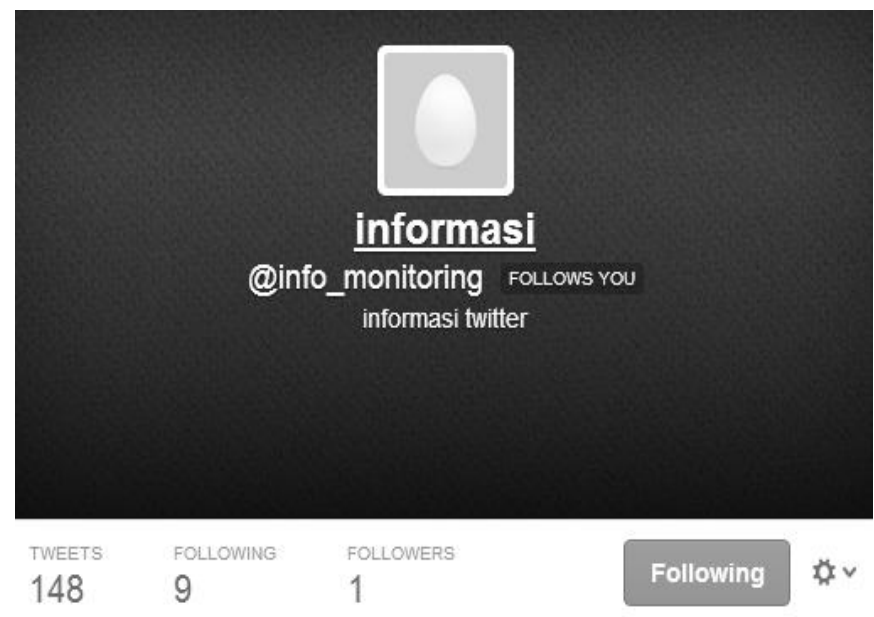

informasi@info_monitoring-Feb6

Ketinggian Air $=38 \mathrm{~cm}$, Siaga Banjir Details

informasi@info_monitoring-Feb 6

Ketinggian Air $=35 \mathrm{~cm}$, Siaga Banjir Details

Go to full profile $\rightarrow$

Gambar 9. Tampilan padaTwitter

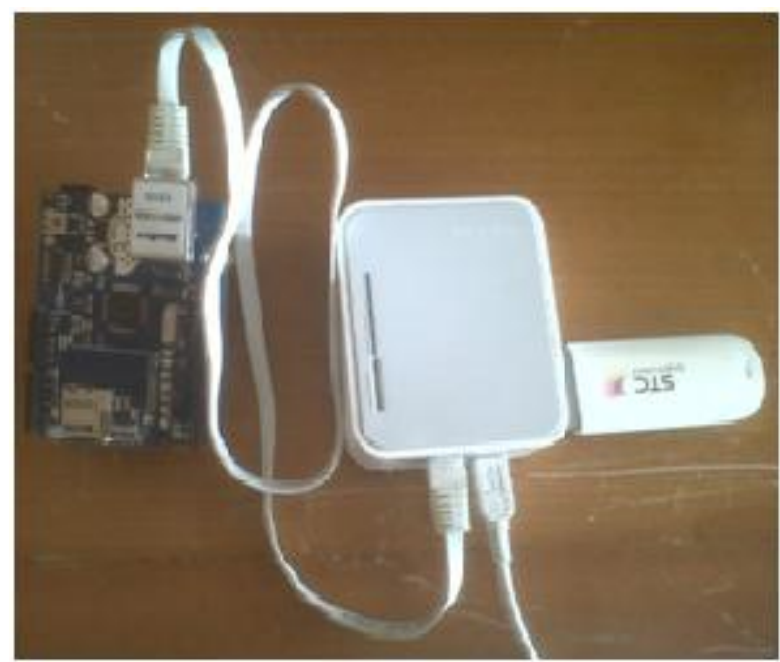

Gambar 10. Perangkat keras Ethernet Shield dengan Arduino.

\section{KESIMPULAN}

Kesimpulan dari penelitian ini adalah sebagai berikut:

1. Pengukuran ketinggian air dengan sensor HC-SR04 sudah dapat ditampilkan pada LCD. Pengukuran air dilakukan pada jarak $3 \mathrm{~cm}$ sampai $50 \mathrm{~cm}$.

2. Pembaruan data ketinggian air dilakukan setiap 1 menit ke media sosial twitter melalui Ethernet Shield.

3. WTV020SD sudah mampu mengeluarkan suara "kondisi bendungan normal" pada ketinggian air $10 \mathrm{~cm}$, suara "waspada banjir" pada ketinggian air $20 \mathrm{~cm}$, suara "siaga banjir" pada ketinggian air $30 \mathrm{~cm}$ dan suara "bahaya banjir" pada ketinggian air $40 \mathrm{~cm}$.

4. Pengukuran ketinggian air di lapangan dan tampilan pada twitter sudah bernilai sama.

\section{DAFTAR PUSTAKA}

[1] __. Christianto Tjahyadi. http: //christianto.tjahyadi.com/ belajar-mikrokontroler/sensor-ultrasonik-hc-sr04.html diakses tgl 7 November 2013

[2] _. LCD http://elektronika-dasar.web.id /teorielektronika/lcd-liquid-cristal-display/ diakses tgl 7 November 2013

[3] Agfianto 2009. Gava Media Belajar Mikrokontroler AT89C51/52/55: Teori dan Aplikasi, Edisi 2 : Yogyakarta.

[4] _... Arduino UNO. http://arduino.cc/en/Main/ArduinoBoardUno/. Diakses tgl 8 November 2013

[5] _. Indotronic. http://www.indotronic.com /product/u-diskaudio-player-sd-card-voice-module-mp3-voice-module diakses $\operatorname{tgl} 7$ November 2013.

[6] Ethernet Shield. http://arduino.cc/ en/Main /ArduinoEthernetShield\#. UwVy72GSw6A. Diakses tgl 7 November 2013

[7] __. Jumlah Pengguna Twitter. http:

//www.tempo.co/read/news/ 2013/12/17/072538043/IndonesiaPengguna-Twitter-Nomor-3-di-Dunia. diakses tgl 17 Desember 2013 